\title{
Feasibility Study of the Use of Handheld NIR Spectrometer for Simultaneous Authentication and Quantification of Quality Parameters in Intact Pineapple Fruits
}

\author{
Charles L. Y. Amuah $\mathbb{D}^{\mathbb{D}},{ }^{1}$ Ernest Teye $\mathbb{D}^{\mathbb{D}},{ }^{2}$ Francis Padi Lamptey $\mathbb{D}^{2},{ }^{2}$ Kwasi Nyandey $\mathbb{D}^{\mathbb{D}}{ }^{1}$ \\ Jerry Opoku-Ansah $\left(\mathbb{D},{ }^{1}\right.$ and Peter Osei-Wusu Adueming $\mathbb{1}^{1}$ \\ ${ }^{1}$ University of Cape Coast, College of Agriculture and Natural Sciences, School of Physical Sciences, Department of Physics, \\ Laser and Fibre Optics Centre, Cape Coast, Ghana \\ ${ }^{2}$ University of Cape Coast, College of Agriculture and Natural Sciences, School of Agriculture, \\ Department of Agricultural Engineering, Cape Coast, Ghana
}

Correspondence should be addressed to Ernest Teye; teyernest@gmail.com

Received 22 March 2019; Revised 16 May 2019; Accepted 17 June 2019; Published 6 August 2019

Academic Editor: Wee Chew

Copyright $\odot 2019$ Charles L. Y. Amuah et al. This is an open access article distributed under the Creative Commons Attribution License, which permits unrestricted use, distribution, and reproduction in any medium, provided the original work is properly cited.

\begin{abstract}
The potential of predicting maturity using total soluble solids (TSS) and identifying organic from inorganic pineapple fruits based on near-infrared (NIR) spectra fingerprints would be beneficial to farmers and consumers alike. In this study, a portable NIR spectrometer and chemometric techniques were combined to simultaneously identify organically produced pineapple fruits from conventionally produced ones (thus organic and inorganic) and also predict total soluble solids. A total of 90 intact pineapple fruits were scanned with the NIR spectrometer while a digital refractometer was used to measure TSS from extracted pineapple juice. After attempting several preprocessing techniques, multivariate calibration models were built using principal component analysis (PCA), $K$-nearest neighbor (KNN), and linear discriminant analysis (LDA) to identify the classes (organic and conventional pineapple fruits) while partial least squares regression (PLSR) method was used to determine TSS of the fruits. Among the identification techniques, the MSC-PCA-LDA model accurately identified organic from conventionally produced fruits at $100 \%$ identification rate. For quantification of TSS, the MSC-PLSR model gave $\mathrm{Rp}=0.851$ and RMSEC $=0.950{ }^{\circ} \mathrm{Brix}$, and $\mathrm{Rc}=0.854$ and $\mathrm{RMSEP}=0.842^{\circ} \mathrm{Brix}$ at 5 principal components in the calibration set and prediction set, respectively. The results generally indicated that portable NIR spectrometer coupled with the appropriate chemometric tools could be employed for rapid nondestructive examination of pineapple quality and also to detect pineapple fraud due to mislabeling of conventionally produced fruits as organic ones. This would be helpful to farmers, consumers, and quality control officers.
\end{abstract}

\section{Introduction}

Pineapple (Ananas comosus (L.) Merr) is the most economically significant crop in the family Bromeliaceae with exceptional juiciness, vibrant tropical flavour, and immense health benefits. Pineapple fruit is a good source of vitamin C, fiber, and other minerals. It also contains sugar, bromalin (protein-digesting enzyme), citric acid, malic acid, vitamins $\mathrm{A}$ and B, and excellent amount of fiber [1]. Quality evaluation and assurance of pineapple fruits before export, during processing, and in the fresh market is a required activity to ensure quality and safety. These are normally based on internal quality traits such as total soluble solids (TSS), firmness, and acidity. However, TSS ( ${ }^{\circ}$ Brix) has been established as the most vital internal quality indicator. For instance, TSS is among the most important internal quality attribute in determining fruit maturity and harvesting time as well as assessing and grading postharvest quality fruits [2].

At present, the conventional technique for the determination of the internal quality parameters of fruits such as pineapple involves destructive means. This method is usually cumbersome and wasteful. It requires specialised 
equipment, elaborate procedures, and trained personnel, which results in high analysis costs and does not allow for the entire fruits produced to be analyzed [3]. Oftentimes, a representative sample is used to predict the entire fruits and this normally leads to misjudgement. Therefore, rapid nondestructive prediction of TSS in pineapple would be of great value in determining the best harvesting time with vital consequence on its eating quality. This would be timely in meeting the ever-increasing consumer demand for consistent high-quality fruits.

Furthermore, the high price enjoyed by selling organically produced pineapples as against conventional ones has led to mislabeling also known as food fraud to gain undue financial advantage. Studies have revealed that consumer demand for organic food is growing and organic agriculture is more profitable due to higher price farmers receive for their produce $[4,5]$. Organic production in general is a system which excludes the use of synthetic fertilizer, pesticides, growth regulators, and other agrochemicals [6]. However, the techniques used for detecting the differences (organically produced fruits such as pineapples from conventional ones) are relatively expensive, destructive, and time consuming and often require elaborate sample preparation. Hence, simultaneous detection of pineapple fruit quality parameters (authenticity and quantification) using portable NIR spectrometer and chemometric technique would be very beneficial. This could offer rapid examination of pineapple fruit quality.

Near-infrared spectroscopy provides an alternative for the determination of pineapple quality parameters. This method provides rapid and nondestructive detection of food quality and safety. It has found its use for qualitative and quantitative analysis in the food industry. NIR spectroscopy is simple, rapid, and nondestructive and requires minimal or no sample preparation. According to other authors, NIR spectroscopy could be one of the most commonly used techniques due to its speediness, noncontact, and low operating cost [7-9]. For fruit quality measurements, NIR spectroscopy has been used to detect nitrate levels in intact pineapple [10], soluble solids content and acidity in kiwifruit [11], and pear internal quality indices [12]. Furthermore, miniaturization of NIR spectroscopy has resulted in the development of commercial handheld or portable spectroscopic systems that offer additional speed, simplicity, and sensitivity. It also presents an ideal tool for agrifood quality evaluation for in situ measurements due to its portability $[13,14]$. Other researchers have used handheld or portable NIR spectrometers to determine fruit quality parameters such as TSS, TA, and sugar content in fruits $[7,15,16]$. Furthermore, Cayuela and Weiland used two portable spectrometers to predict several quality parameters in intact oranges [17] while Sánchez et al. studied by improving the performance of portable NIR instrument for intact nectarines [18]. However, and to the best of our knowledge, no researcher has investigated the feasibility of using portable NIR spectrometer coupled with chemometric techniques to simultaneously discriminate organically produced pineapples and conventional ones and also predict total soluble solids (TSS) nondestructively.
Therefore, the main objective of this study was to evaluate the potential of using portable NIR spectrometer for rapid and nondestructive identification and quantification of pineapple quality parameters such as TSS of intact pineapple fruits. The specific objectives were to determine the best multivariate technique for identification and to predict TSS of intact pineapple fruits.

\section{Materials and Methods}

2.1. Pineapple Fruit Samples. In this study, 90 pieces of sugarloaf pineapple fruits at different maturity stages were obtained directly from pineapple farmers in the Central Region of Ghana and transported to the University of Cape Coast, School of Agriculture Teaching and Research Laboratory. These fruits comprise 30 pieces of organically produced pineapple fruits and 60 pieces of conventionally produced pineapple fruits. The fruits were then stored at $26^{\circ} \mathrm{C}\left( \pm 1^{\circ} \mathrm{C}\right)$ for two days before measurements were taken.

2.2. Sample Spectra Acquisition. The spectrum of each pineapple was collected in the reflectance mode using a handheld spectrometer $\left(\mathrm{SCIO}^{\mathrm{TM}}\right)$ with spectra range between $740 \mathrm{~nm}$ and $1070 \mathrm{~nm}$ in a $1 \mathrm{~nm}$ resolution for spectra data recording. For each fruit, the lower part was scanned three times after rotating it at $120^{\circ}$. The scanning was done at an ambient temperature of $26 \pm 1^{\circ} \mathrm{C}$ with a humidity of $60 \%$. Figure 1 shows the setup of the scanning processing using SCIO NIR spectrometer.

2.3. Reference Measurements (TSS $/{ }^{\circ}$ Brix). Total soluble solids (TSS) contents were determined using a digital refractometer (model: PAL-1, ${ }^{\circ}$ Brix range of $0-35 \%$; Atago, Tokyo, Japan) according to the methods described by others $[15,16,19]$. For each pineapple fruit, the base was selected and juiced. About $1.0 \mathrm{ml}$ juice was then taken for TSS measurement with a digital refractometer. Triplicate measurements were performed and the results expressed as ${ }^{\circ}$ Brix.

2.4. Data Partition. The raw dataset (from the 90 samples) after preprocessing with suitable techniques was divided into two subsets, calibration set (data from 68 samples) for developing the model and prediction set (data from 22 samples) for evaluating the predictive ability of the constructed models. To avoid bias, $75 \%$ of data from both organic and inorganic samples were selected as the calibration set while the remaining data were selected as the prediction set. As shown in Table 1, the members in each set were selected in order to come to a $3 / 1$ division of calibration set/prediction set.

2.5. Software Device. Spectra data recordings stored in a cloud-based dataset with their corresponding reference value for time of scanning were downloaded using a research license of SCIO lab and imported to MATLAB version 9.5.0 (Mathworks Inc., USA) with Windows 10 Basic for data 


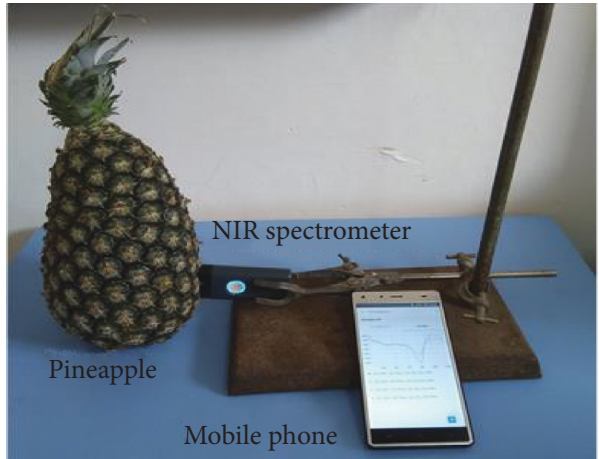

FIgURE 1: Setup of scanning processing.

processing for all preprocessing treatments and multivariate algorithms.

2.6. Spectra Preprocessing Techniques. The average raw spectra of the pineapple samples are shown in Figure 2(a) while the other pretreatment spectra are also shown in Figures 2(b) and 2(c). The activity of preprocessing of the spectra data is an integral part of modelling to eliminate background information and noise from the useful properties of the scanned samples [3, 20]. In this research, two spectra preprocessing techniques (mean centering (MC) and multiplicative scatter correction (MSC)) were applied because the models developed using the raw spectra data did not give the desired results.

MC is normally used as resolution enhancement method, and it is known to work by simply adjusting a dataset to reposition the centroid of the data to the origin of the coordinate system [21].

$$
S_{i}=S_{i j}-S_{i m}
$$

MSC on the other hand is a useful preprocessing technique for the correction of scattered light and inclination of baseline variation. For more information, refer to other authors $[21,22]$. For spectra with additive effect $\left(x_{i}\right)$ and multiplicative effect $\left(y_{i}\right)$, it can be represented as

$$
S_{i}=x_{i}+y_{i} S_{m}+e_{i},
$$

where $S_{m}$ is the mean of the set of spectra. The residual error vector $e_{i}$ gives information about the random noise. Hence, the MSC-corrected spectra are calculated as

$$
S_{i \text { corrected }}=\frac{\left(S_{i}-x_{i}\right)}{y_{i}},
$$

where for a measured data containing a set of spectra $S_{i}$ $(i=1,2, \ldots, K)$ with data points $S_{i j}(j=1,2, \ldots, N)$, the mean of these data could be represented as $S_{i m}$, which is the mean of that spectrum.

2.7. Principal Component Analysis (PCA). PCA is an unsupervised data description and dimension reduction techniques which is mostly used to deal with large spectra data [23]. It normally involves the first step of data analysis in order to detect patterns from the data matrix as it brings out visualized data trends in dimensional space [24]. For more information, refer to these authors [25].

2.8. Multivariate Models. The development of computers and software programmes is making chemometric techniques a very powerful tool for processing NIR spectra data as it overcomes the difficulty of multicollinearity and gives scientific statistical inferences for meaningful conclusions to experimental results $[26,27]$. Choosing the best method is the next challenge as it is quite a cumbersome process since there existed quite a lot of types. In this research, $K$-nearest neighbor (KNN) and linear discriminant analysis (LDA) were employed comparatively.

$K$-nearest neighbor is a linear and nonparametric classification method which works based on a distance function that measures the difference or similarity between two stances $[28,29]$. For KNN, parameter $K$ influences the results of the classification model; hence, the choice of $K$ is normally optimized by calculating its potential with several $K$ values (normally small $K$ values of 3 or 5 ). It must be known that KNN cannot work well if large differences are present in the number of samples in each class [25]. This therefore makes KNN tool a more suitable technique for modelling similar class groupings.

Linear discriminant analysis is a linear and parametric supervised pattern recognition technique which has found it useful for analyzing spectra data. It works by finding linear combination of features which brings out clearly the ratio of between-class variance and reduces the ratio of within-class variance [30]. For more information, refer to [25]. It is important to note that the performance of LDA is based on the number of principal component factors.

2.9. Partial Least Squares (PLS). Partial least squares (PLS) is a well-known linear multivariate method used for spectra data processing and it can analyze data with strong collinear, noisy, and redundant variables. For more information, refer to $[31,32]$. The results of the PLS model are normally evaluated by using three main parameters, namely, the root mean square error of cross-validation (RMSECV), the root mean square error of prediction (RMSEP), and the correlation coefficient $(R)$, among others [33]. These parameters were calculated by the following equations:

$$
\begin{aligned}
\text { RMSECV } & =\sqrt{\frac{\sum_{i=1}^{n}\left(\hat{y}_{\backslash i}-y_{i}\right)^{2}}{n}}, \\
\text { RMSEP } & =\sqrt{\frac{\sum_{i}^{n}\left(y_{i}-\hat{y}_{i}\right)^{2}}{n},} \\
R & =\sqrt{1-\frac{\sum_{i=1}^{n}\left(\hat{y}_{i}-y_{i}\right)^{2}}{\sum_{i=1}^{n}\left(y_{i}-\bar{y}\right)^{2}}},
\end{aligned}
$$

where $n=$ the number of samples, $y_{i}=$ the reference measurement results for sample $i, \widehat{y}_{\backslash i}=$ the estimated result for 
TABLE 1: Reference measurement of TSS ( ${ }^{\circ}$ Brix) of total samples used.

\begin{tabular}{lccc}
\hline Subsets & \multicolumn{2}{c}{ Number of samples } & Total soluble solids (TSS) content \\
& & Range $\left({ }^{\circ}\right.$ Brix $)$ & Mean $\left({ }^{\circ}\right.$ Brix $)$
\end{tabular}

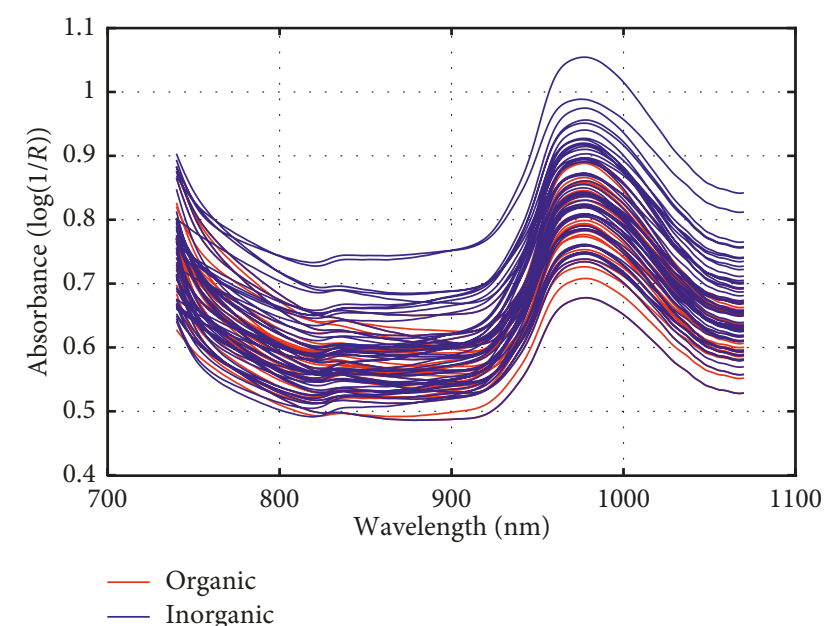

(a)

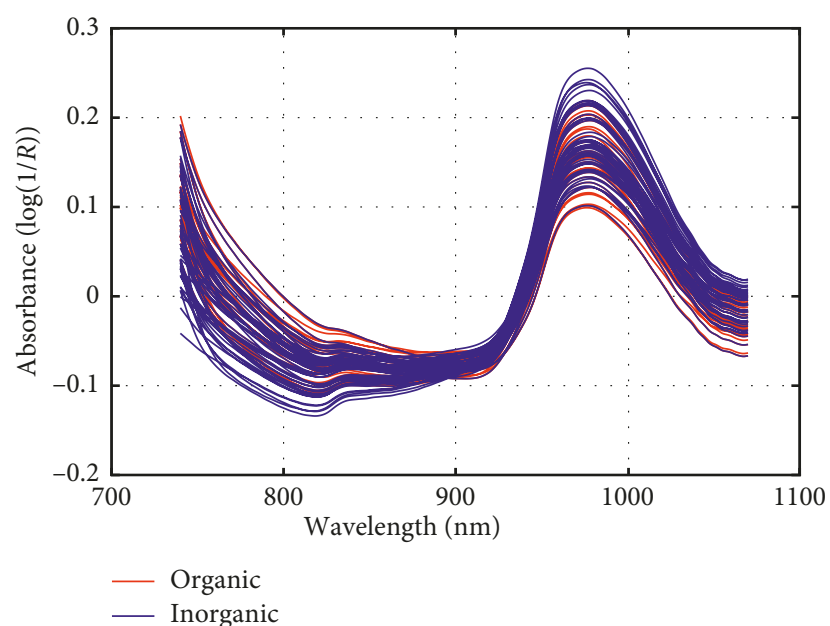

(b)

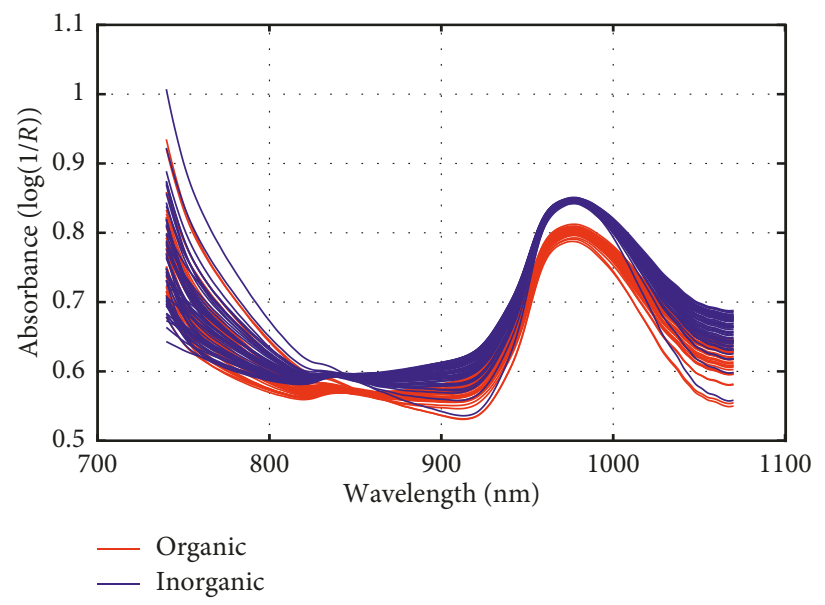

(c)

FIgURE 2: NIR spectra of pineapple fruits. (a) Raw, (b) pretreatment with MC, and (c) pretreatment with MSC.

sample $i$ when the model is constructed with sample $i$ removed, $\widehat{y}_{i}=$ the estimated results of the model for the sample $i$, and $\bar{y}=$ the mean of the reference measurement results for all samples.

\section{Results and Discussion}

3.1. Spectra Presentation/Analysis. The fingerprint from the spectra dataset was used to create the statistical models. It could be observed from the spectra profile in Figures 2(a)2 (c) that the major peaks are around 960-1050 $\mathrm{nm}$. The wavelength range corresponds to $\mathrm{O}-\mathrm{H}$ 2nd overtone and $\mathrm{N}-\mathrm{H}$ 2nd overtone, which represents $\mathrm{H}_{2} \mathrm{O}, \mathrm{ROH}, \mathrm{ArOH}$ ( $\mathrm{OH}$ bond on the aromatic group), and $\mathrm{NH}_{2}$ functional groups [34]. These groups are familiar with major constituents of water, glucose, sucrose, and cellulose of pineapples. TSS is an organic molecule that contains $\mathrm{C}-\mathrm{H}, \mathrm{O}-\mathrm{H}, \mathrm{C}-\mathrm{O}$, and $\mathrm{C}-\mathrm{C}$ bonds, and NIR spectroscopy could be used to nondestructively measure this molecule [35, 36]. After preprocessing of the spectra dataset with MC and MSC, a clear separation between organic and inorganic pineapple fruits appeared in MSC pretreatment spectra profile as shown in Figure 2(c). This suggests that organic and inorganic pineapple fruits could be differentiated within $800 \mathrm{~nm}$ and $1070 \mathrm{~nm}$ range using MSC pretreatment technique. The MSC is therefore a useful tool for correcting baseline shift and light scattering problems related to the spectral dataset as mentioned by other authors [22]. 


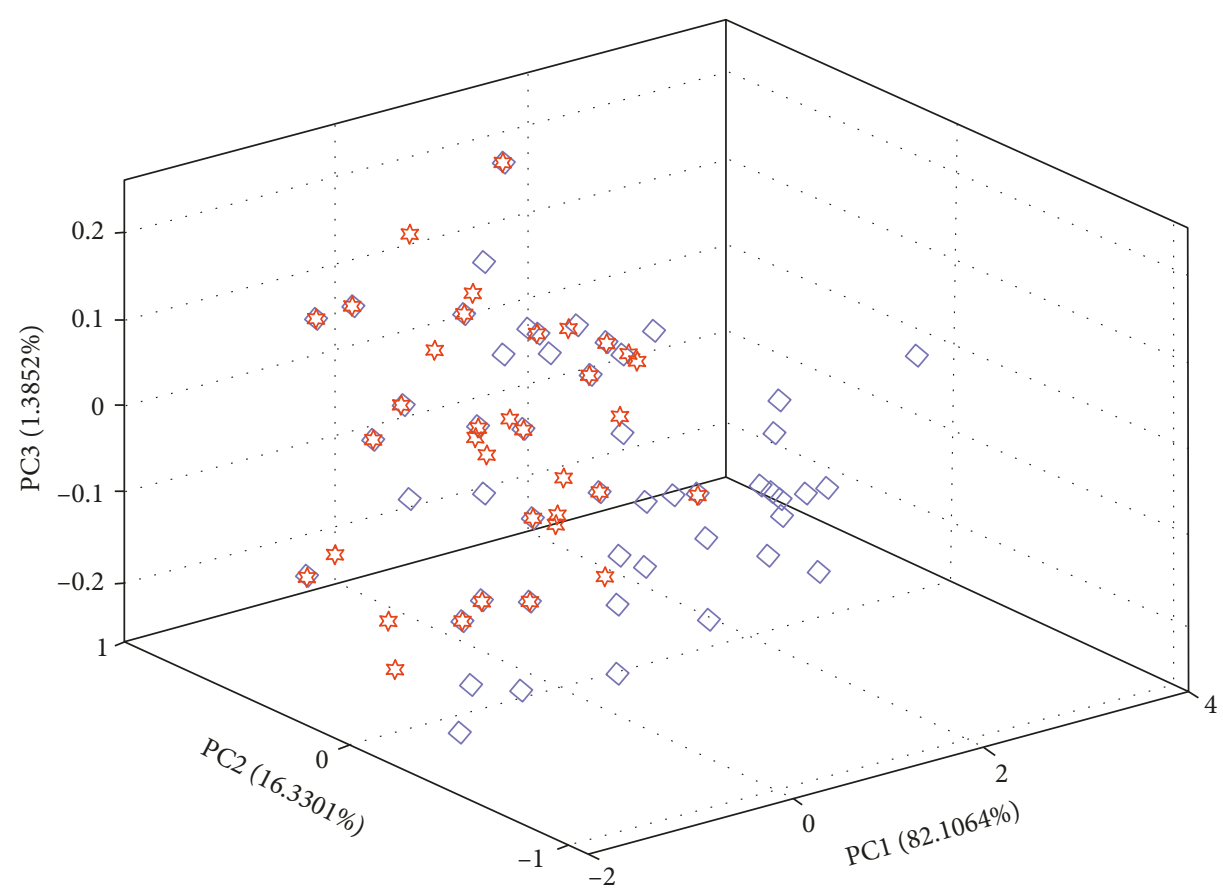

is Organic

$\diamond$ Inorganic

(a)

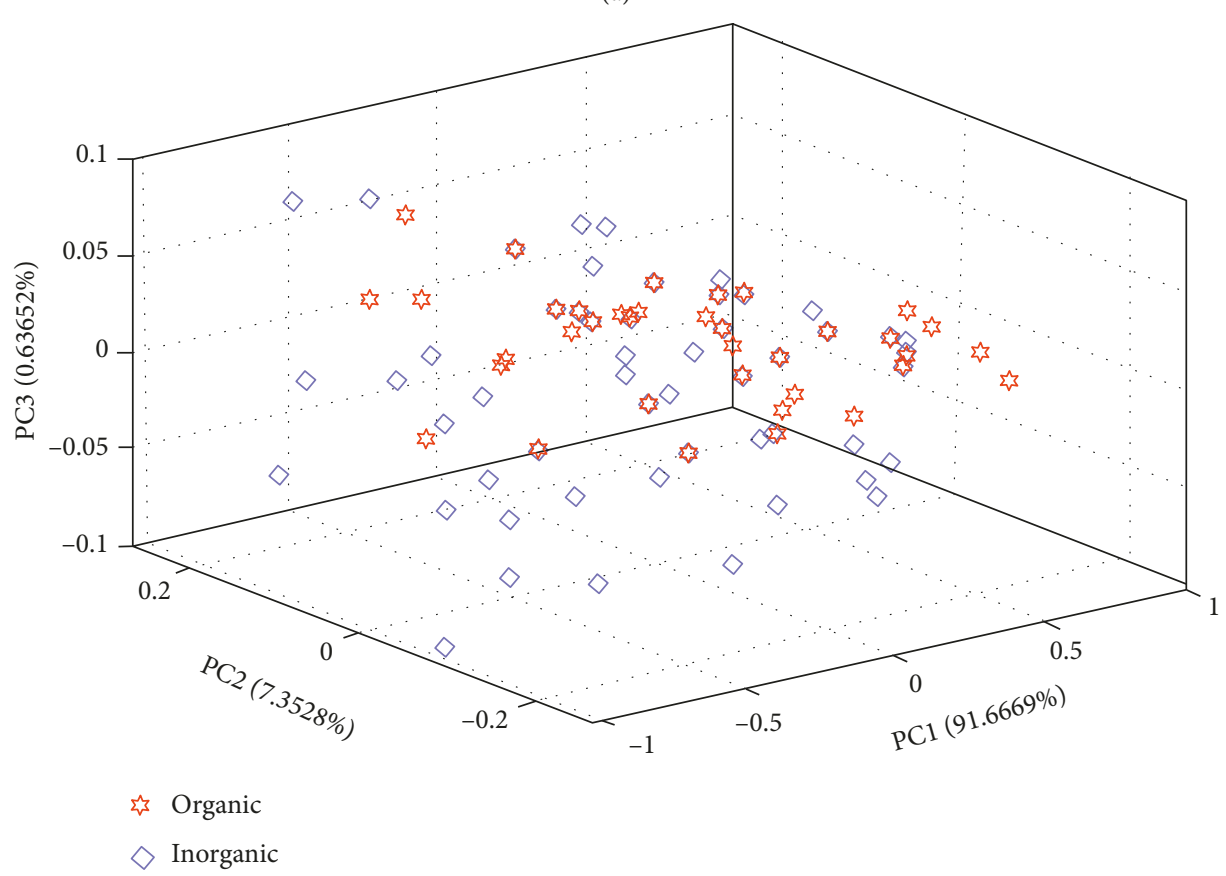

(b)

Figure 3: Continued. 


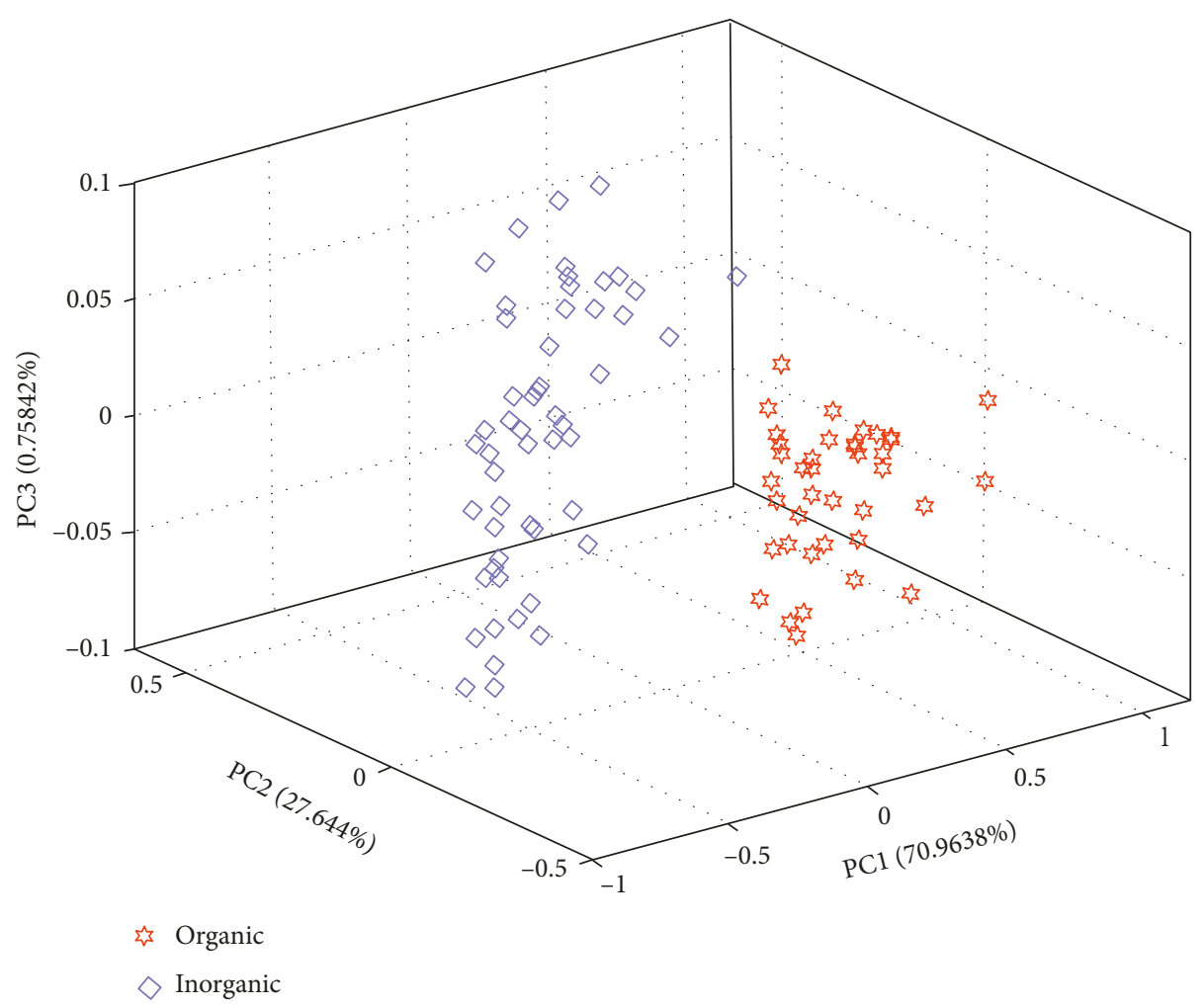

(c)

Figure 3: PCA score plot of spectra data. (a) Raw, (b) preprocessed with MC, and (c) preprocessed with MSC. MSC with PCA technique gave a separation with clear cluster trend.

3.2. Principal Component Analysis (PCA). Principal component analysis was used to identify cluster trend in the spectra data. From the results obtained, it was observed that PCA done on raw and MC preprocessed spectra data did not give any clear cluster trends or separations as shown in Figures 3(a) and 3(b). However, MSC-PCA technique gave a separation with clear cluster trend as shown in Figure 2(c). Again this further proves the unique characteristics of MSC as an effective technique for baseline light scattering corrections as proposed by Geladi and coworkers [22]. PCA was able to identify the most important directions of the variability in the multivariate data space ( $X$ matrix) and to determine the primary phenomena in the spectra dataset [19]. The PCs (PC1, PC2, and PC3) contain spectra information and its corresponding chemical compositional information hence accounted for $99.36 \%$ of the total variance that existed for the 90 pineapple samples used in this study. Pineapples have a considerable difference in their chemical properties according to their preharvest activities and postharvest practices that categorize them as either organic or inorganic.

3.3. Classification Models. In this study, KNN and LDA were attempted for developing classification models for classifying organic and inorganic pineapple fruits.

The results of the classification models are shown in Table 2. The two classification models used performed well using MSC-PCA dataset. KNN and LDA had classification rate above $98 \%$ in both the calibration set and prediction set at optimal principal components $(\mathrm{PCs})=3$, respectively. This means MSC-PCA preprocessing enhanced the performance of both KNN and LDA as compared to raw and $\mathrm{MC}$ dataset. On the other hand, LDA was slightly superior to KNN in the training set. This means LDA was well able to find the linear combination of features and the resulting combination used was a better linear classifier. More so, it could be explained that the good accuracy obtained by the model could be as a result of complex distinct organoleptic and nutritional properties between organically grown pineapple fruits as against conventionally grown ones. This phenomenon is further supported by the evidence that organic production excludes the use of synthetic fertilizer, pesticides, growth regulators, and other chemicals [6] and impact of the fruit's quality and safety due to chemical residues. Other studies have also revealed that organically produced pineapple fruits comparatively have high vitamin $\mathrm{C}$ and moderate acidity [4] as well as highest total soluble solids contents [37].

3.4. Quantification Model. Partial least squares model was used for the determination of TSS ( ${ }^{\circ}$ Brix) in both organic and inorganic pineapple fruits. From Figure 4, the measured values correlated linearly with NIR predicted measurements. However, there were some few outliers which subsequently 
TABLE 2: The performance of classification models influenced by preprocessing techniques.

\begin{tabular}{|c|c|c|c|c|}
\hline \multicolumn{2}{|c|}{ Model } & \multirow{2}{*}{ Number of principal components } & \multicolumn{2}{|c|}{ Correct classification rate (\%) } \\
\hline & & & Calibration set (68) & Prediction set (22) \\
\hline \multirow{3}{*}{$\mathrm{KNN}$} & Raw & 3 & 45.56 & 50.00 \\
\hline & $\mathrm{MC}$ & 3 & 52.22 & 60.00 \\
\hline & MSC & 3 & 98.89 & 100.00 \\
\hline \multirow{3}{*}{ LDA } & Raw & 3 & 61.11 & 66.67 \\
\hline & $\mathrm{MC}$ & 3 & 55.56 & 50.00 \\
\hline & MSC & 3 & 100.00 & 100.00 \\
\hline
\end{tabular}

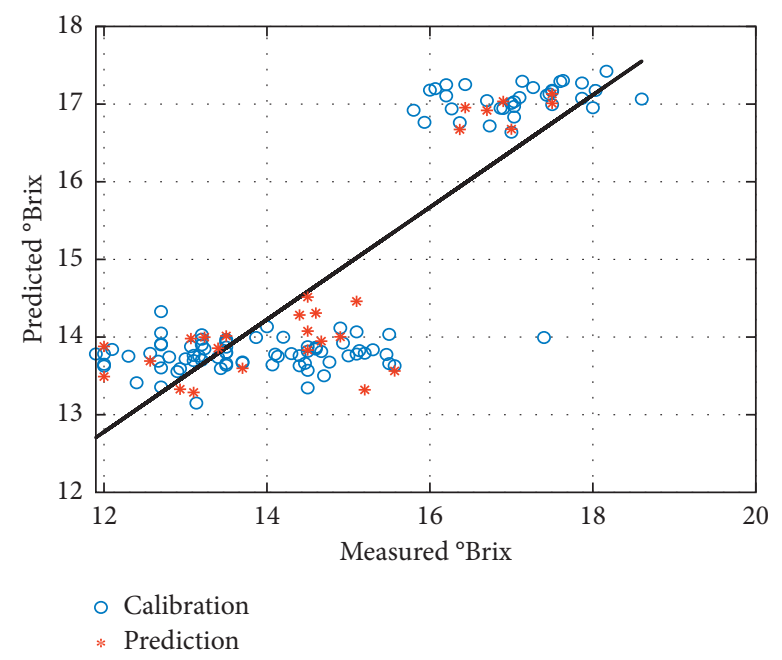

FIGURE 4: Reference measured versus NIR prediction of TSS in the calibration set and prediction set.

affected the PLS model. From Table 3, it could be seen that the MSC-PLS model was the best comparatively with parameters of $\mathrm{Rc}=0.851$, and $\mathrm{RMSEC}=0.950{ }^{\circ} \mathrm{Brix}$ in the calibration set while $\mathrm{Rp}=0.854$ and $\mathrm{RMSEP}=0.842^{\circ} \mathrm{Brix}$ in the prediction set. This result indicates that proper preprocessing technique is an efficient way to improve the accuracy of the PLS model [33]. For a good model, $R$ value should be close to unity while RMSEC and RMSEP should be close to zero. The weaknesses of this MSC-PLS model could be attributed to the characteristics of the PLS model, because classic PLS model was built using full spectrum range, which normally consists of useful and irrelevant or redundant information (noise). The noisy spectrum normally reduces the performance of the model. Hence, to improve this model for intact pineapple quality evaluation, other known PLS types should be investigated while comparing with other nonlinear algorithms. Notwithstanding, the results compare favourable with those found by other authors for using VISSWNIR spectroscopy for predicting soluble solids content in pineapple fruits [15]. More so, it must be stated that through favourable statistical correlations, the NIR multivariate models predicted the ${ }^{\circ}$ Brix values.

3.5. Selection of Vital Wavelengths. When developing the PLS model, there is the need to consider how much each wavelength contributes to the final outcome. Figure 5 shows PLS loading weights of the best model and this explains how
TABLE 3: Prediction results of PLS models under different pretreatment methods.

\begin{tabular}{lccccc}
\hline Pretreatment & Factors & $R$ & $\begin{array}{c}\text { Calibration } \\
\text { RMSEC } \\
\left({ }^{\circ} \text { Brix) }\right.\end{array}$ & $R$ & RMSEP ( ${ }^{\circ}$ Brix) \\
\hline Raw & 5 & 0.559 & 1.499 & 0.617 & 1.274 \\
MC & 6 & 0.504 & 1.563 & 0.539 & 1.363 \\
MSC & 5 & 0.851 & 0.950 & 0.854 & 0.842 \\
\hline
\end{tabular}

the complexity of the PLS model was developed. The loadings show how well the wavelength was taken into consideration by the model components. It is used to understand how much each $x$-variable (wavelengths) contributes to the meaningful variation in the data and to interpret variable relationships as well as interpret the meaning of each model component [38]. The loading weights were normalised so that the length and directions could be made meaningful. From Figure 5, we can see several peaks at certain wavelengths $(754,760,823,850,884,901$, 910, 950, and $960 \mathrm{~nm}$ ) which are considered to be more useful for the developed PLS model used for determining total soluble solids (TSS, ${ }^{\circ}$ Brix) content in pineapples. These vital observed wavelengths in this study are closely related to the chemical composition in pineapple fruits. Specifically, these wavelengths are related to the third overtone region comprising $\mathrm{OH}$ and $\mathrm{CH}$ stretching vibrations of sucrose solutions [39], an important component of TSS. For 


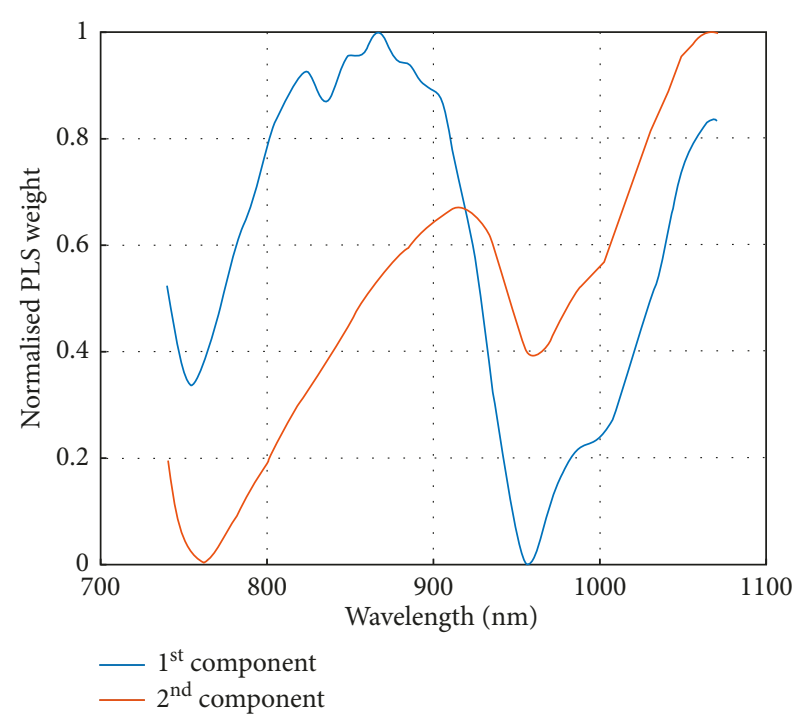

FIGURE 5: PLS loading weights versus wavelength of the top two latent variables.

example, the wavelengths at 910,950, and $960 \mathrm{~nm}$ are related to the chemical group of $\mathrm{C}-\mathrm{H}$ and $\mathrm{O}-\mathrm{H}$ which are attributed to TSS, while the region of $750-820 \mathrm{~nm}$ reveals sucrose, glucose, and fructose [9, 39].

\section{Conclusion}

The research has shown the potential of handheld NIR spectroscopic technique for rapid nondestructive measurements of pineapple quality. MSC gave the best PCA cluster trend with clear separation in the first three PCs. The overall results showed that handheld spectrometer coupled with MSC-PCA+LDA model could be used to identify organically and conventionally grown intact pineapple fruits with $100 \%$ identification rate in both the training set and prediction set, respectively. On the other hand, PLS regression model could be used for predicting TSS $\left({ }^{\circ} \mathrm{Brix}\right)$ with $\mathrm{RMSEC}=0.95$ and $\mathrm{RMSEP}=0.84$ at 5 factors with an accuracy of $85 \%$ in both the calibration set and prediction set, respectively. There is a potential of these models to be imported into mobile phone technology for effective allround application.

\section{Data Availability}

The data used to support the findings of the study are available from the corresponding author upon request.

\section{Conflicts of Interest}

The authors declare that there are no conflicts of interest.

\section{Acknowledgments}

The authors highly appreciate the support provided by the University of Cape Coast, Agilent Foundation, and Mars. The supply of fresh pineapple fruits by ACOPPS and AMOPPA pineapple farmers in the Central Region is highly acknowledged. The authors appreciate proofreading assistance provided by Mrs. Winifred Akpene Teye.

\section{References}

[1] F. Hossain, "World pineapple production: an overview," African Journal of Food, Agriculture, Nutrition and Development, vol. 16, no. 4, pp. 11443-11456, 2016.

[2] Y. Peng and R. Lu, "Analysis of spatially resolved hyperspectral scattering images for assessing apple fruit firmness and soluble solids content," Postharvest Biology and Technology, vol. 48, no. 1, pp. 52-62, 2008.

[3] V. Cortés, C. Ortiz, N. Aleixos, J. Blasco, S. Cubero, and P. Talens, "A new internal quality index for mango and its prediction by external visible and near-infrared reflection spectroscopy," Postharvest Biology and Technology, vol. 118, pp. 148-158, 2016.

[4] M. Owureku-Asare, J. Agyei-Amponsah, S. W. K. Agbemavor et al., "Effect of organic fertilizers on physical and chemical quality of sugar loaf pineapple (Ananas comosus $\mathrm{L}$ ) grown in two ecological sites in Ghana," African Journal of Food, Agriculture, Nutrition and Development, vol. 15, no. 2, pp. 9982-9995, 2015.

[5] S. Bolwig, P. Gibbon, and S. Jones, "The economics of smallholder organic contract farming in tropical Africa," World Development, vol. 37, no. 6, pp. 1094-1104, 2009.

[6] D. B. Singh, "Comparative study of organic and conventional farming of pineapple," Asian Journal of Horticulture, vol. 4, no. 1 , pp. 1-4, 2009.

[7] J. Li, Q. Wang, L. Xu, X. Tian, Y. Xia, and S. Fan, “Comparison and optimization of models for determination of sugar content in pear by portable Vis-NIR spectroscopy coupled with wavelength selection algorithm," Food Analytical Methods, vol. 12, no. 1, pp. 12-22, 2019.

[8] B. M. Nicolaï, K. Beullens, E. Bobelyn et al., "Nondestructive measurement of fruit and vegetable quality by means of NIR spectroscopy: a review," Postharvest Biology and Technology, vol. 46, no. 2, pp. 99-118, 2007.

[9] H. Wang, J. Peng, C. Xie, Y. Bao, and Y. He, "Fruit quality evaluation using spectroscopy technology: a review," Sensors, vol. 15, no. 5, pp. 11889-11927, 2015.

[10] S. Srivichien, A. Terdwongworakul, and S. Teerachaichayut, "Quantitative prediction of nitrate level in intact pineapple using Vis-NIRS," Journal of Food Engineering, vol. 150, pp. 29-34, 2015.

[11] A. Moghimi, M. H. Aghkhani, A. Sazgarnia, and M. Sarmad, "Vis/NIR spectroscopy and chemometrics for the prediction of soluble solids content and acidity $(\mathrm{pH})$ of kiwifruit," Biosystems Engineering, vol. 106, no. 3, pp. 295-302, 2010.

[12] Y. Liu, X. Chen, and A. Ouyang, "Nondestructive determination of pear internal quality indices by visible and near-infrared spectrometry," LWT-Food Science and Technology, vol. 41, no. 9, pp. 1720-1725, 2008.

[13] P. M. Santos, E. R. Pereira-Filho, and L. E. Rodriguez-Saona, "Application of hand-held and portable infrared spectrometers in bovine milk analysis," Journal of Agricultural and Food Chemistry, vol. 61, no. 6, pp. 1205-1211, 2013.

[14] L.-M. Yuan, L. Sun, J.-R. Cai, and H. Lin, "A preliminary study on whether the soluble solid content and acidity of oranges predicted by near infrared spectroscopy meet the sensory degustation," Journal of Food Process Engineering, vol. 38, no. 4, pp. 309-319, 2015.

[15] K. S. Chia, H. Abdul Rahim, and R. Abdul Rahim, "Prediction of soluble solids content of pineapple via non-invasive low 
cost visible and shortwave near infrared spectroscopy and artificial neural network," Biosystems Engineering, vol. 113, no. 2, pp. 158-165, 2012.

[16] E. J. N. Marques, S. T. de Freitas, M. F. Pimentel, and C. Pasquini, "Rapid and non-destructive determination of quality parameters in the 'Tommy Atkins' mango using a novel handheld near infrared spectrometer," Food Chemistry, vol. 197, pp. 1207-1214, 2016.

[17] J. A. Cayuela and C. Weiland, "Intact orange quality prediction with two portable NIR spectrometers," Postharvest Biology and Technology, vol. 58, no. 2, pp. 113-120, 2010.

[18] M.-T. Sánchez, M.-J. De la Haba, J.-E. Guerrero, A. GarridoVaro, and D. Pérez-Marín, "Testing of a local approach for the prediction of quality parameters in intact nectarines using a portable NIRS instrument," Postharvest Biology and Technology, vol. 60, no. 2, pp. 130-135, 2011.

[19] M. Sun, D. Zhang, L. Liu, and Z. Wang, "How to predict the sugariness and hardness of melons: a near-infrared hyperspectral imaging method," Food Chemistry, vol. 218, pp. 413-421, 2017.

[20] M. Blanco and I. Villarroya, "NIR spectroscopy: a rapid-response analytical tool," TrAC Trends in Analytical Chemistry, vol. 21, no. 4, pp. 240-250, 2002.

[21] Y. Ozaki, W. F. McClure, and A. A. Christy, Near-Infrared Spectroscopy in Food Science and Technology, John Wiley \& Sons, Hoboken, NJ, USA, 2006.

[22] P. Geladi, D. MacDougall, and H. Martens, "Linearization and scatter-correction for near-infrared reflectance spectra of meat," Applied Spectroscopy, vol. 39, no. 3, pp. 491-500, 1985.

[23] W. Kong, C. Zhang, F. Liu, P. Nie, and Y. He, "Rice seed cultivar identification using near-infrared hyperspectral imaging and multivariate data analysis," Sensors, vol. 13, no. 7, pp. 8916-8927, 2013.

[24] B. K. Lavine and N. Mirjankar, "Clustering and classification of analytical data," in Encyclopedia of Analytical Chemistry: Applications, Theory and Instrumentation, John Wiley \& Sons, Hoboken, NJ, USA, 2006.

[25] L. A. Berrueta, R. M. Alonso-Salces, and K. Héberger, "Supervised pattern recognition in food analysis," Journal of Chromatography A, vol. 1158, no. 1-2, pp. 196-214, 2007.

[26] Y. Roggo, P. Chalus, L. Maurer, C. Lema-Martinez, A. Edmond, and N. Jent, "A review of near infrared spectroscopy and chemometrics in pharmaceutical technologies," Journal of Pharmaceutical and Biomedical Analysis, vol. 44, no. 3, pp. 683-700, 2007.

[27] E. Teye, X. Huang, L. K. Sam-Amoah et al., "Estimating cocoa bean parameters by FT-NIRS and chemometrics analysis," Food Chemistry, vol. 176, pp. 403-410, 2015.

[28] R. O. Duda, P. E. Hart, and D. G. Stork, Pattern Classification, John Wiley \& Sons, Hoboken, NJ, USA, 2012.

[29] L. Jiang, Z. Cai, D. Wang, and S. Jiang, "Survey of improving K-nearest-neighbor for classification," in Proceedings of the Fourth International Conference on Fuzzy Systems and Knowledge Discovery FSKD 2007, IEEE, Haikou, China, August 2007.

[30] Q. Chen, J. Cai, X. Wan, and J. Zhao, “Application of linear/ non-linear classification algorithms in discrimination of pork storage time using Fourier transform near infrared (FT-NIR) spectroscopy," LWT-Food Science and Technology, vol. 44, no. 10, pp. 2053-2058, 2011.

[31] E. Teye and X. Huang, "Novel prediction of total fat content in cocoa beans by FT-NIR spectroscopy based on effective spectral selection multivariate regression," Food Analytical Methods, vol. 8, no. 4, pp. 945-953, 2015.
[32] S. Wold, M. Sjöström, and L. Eriksson, "PLS-regression: a basic tool of chemometrics," Chemometrics and Intelligent Laboratory Systems, vol. 58, no. 2, pp. 109-130, 2001.

[33] X. Guan, J. Liu, K. Huang, J. Kuang, and D. Liu, "Evaluation of moisture content in processed apple chips using NIRS and wavelength selection techniques," Infrared Physics \& Technology, vol. 98, pp. 305-310, 2019.

[34] H. Cen and Y. He, "Theory and application of near infrared reflectance spectroscopy in determination of food quality," Trends in Food Science \& Technology, vol. 18, no. 2, pp. 72-83, 2007.

[35] G. Giovanelli, N. Sinelli, R. Beghi, R. Guidetti, and E. Casiraghi, "NIR spectroscopy for the optimization of postharvest apple management," Postharvest Biology and Technology, vol. 87, pp. 13-20, 2014.

[36] T. Ma, X. Li, T. Inagaki, H. Yang, and S. Tsuchikawa, "Noncontact evaluation of soluble solids content in apples by near-infrared hyperspectral imaging," Journal of Food Engineering, vol. 224, pp. 53-61, 2018.

[37] M. Darnaudery, P. Fournier, and M. Léchaudel, "Low-input pineapple crops with high quality fruit: promising impacts of locally integrated and organic fertilisation compared to chemical fertilisers," Experimental Agriculture, vol. 54, no. 2, pp. 286-302, 2018.

[38] D. Suhandy and M. Yulia, "The use of partial least square regression and spectral data in UV-visible region for quantification of adulteration in Indonesian palm civet coffee," International Journal of Food Science, vol. 2017, Article ID 6274178, 7 pages, 2017.

[39] M. Golic, K. Walsh, and P. Lawson, "Short-wavelength nearinfrared spectra of sucrose, glucose, and fructose with respect to sugar concentration and temperature," Applied Spectroscopy, vol. 57, no. 2, pp. 139-145, 2003. 

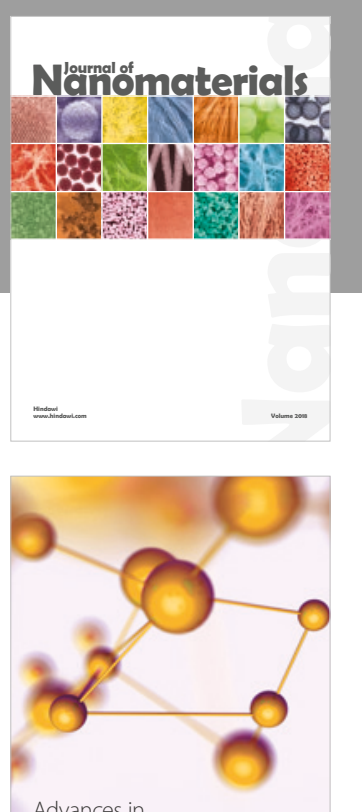

Physical Chemistry
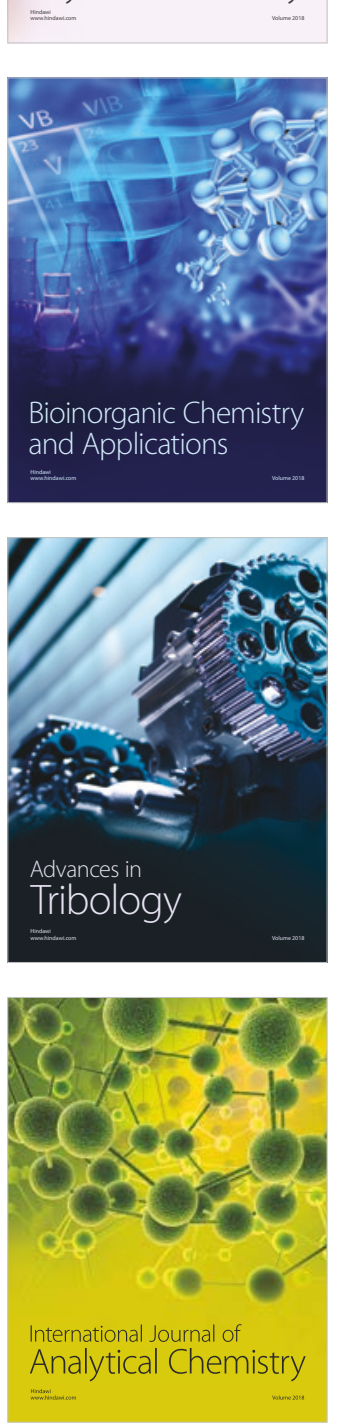

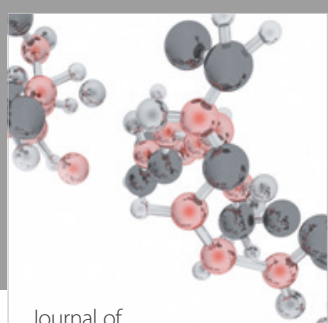

Analytical Methods

in Chemistry

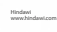

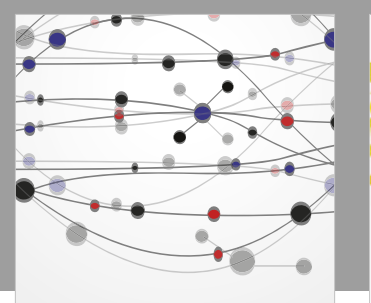

The Scientific World Journal

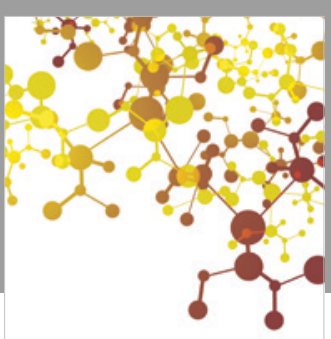

Journal of

Applied Chemistry
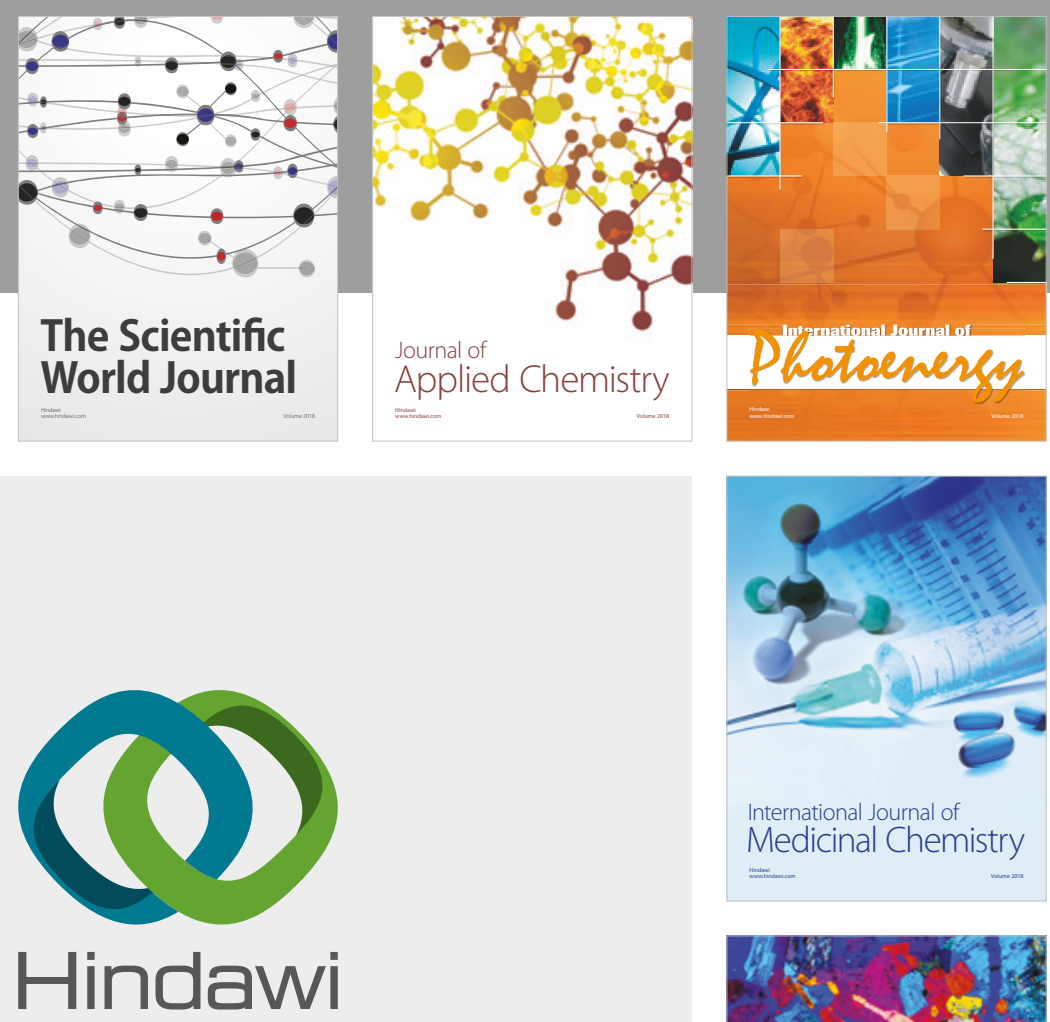

Submit your manuscripts at

www.hindawi.com
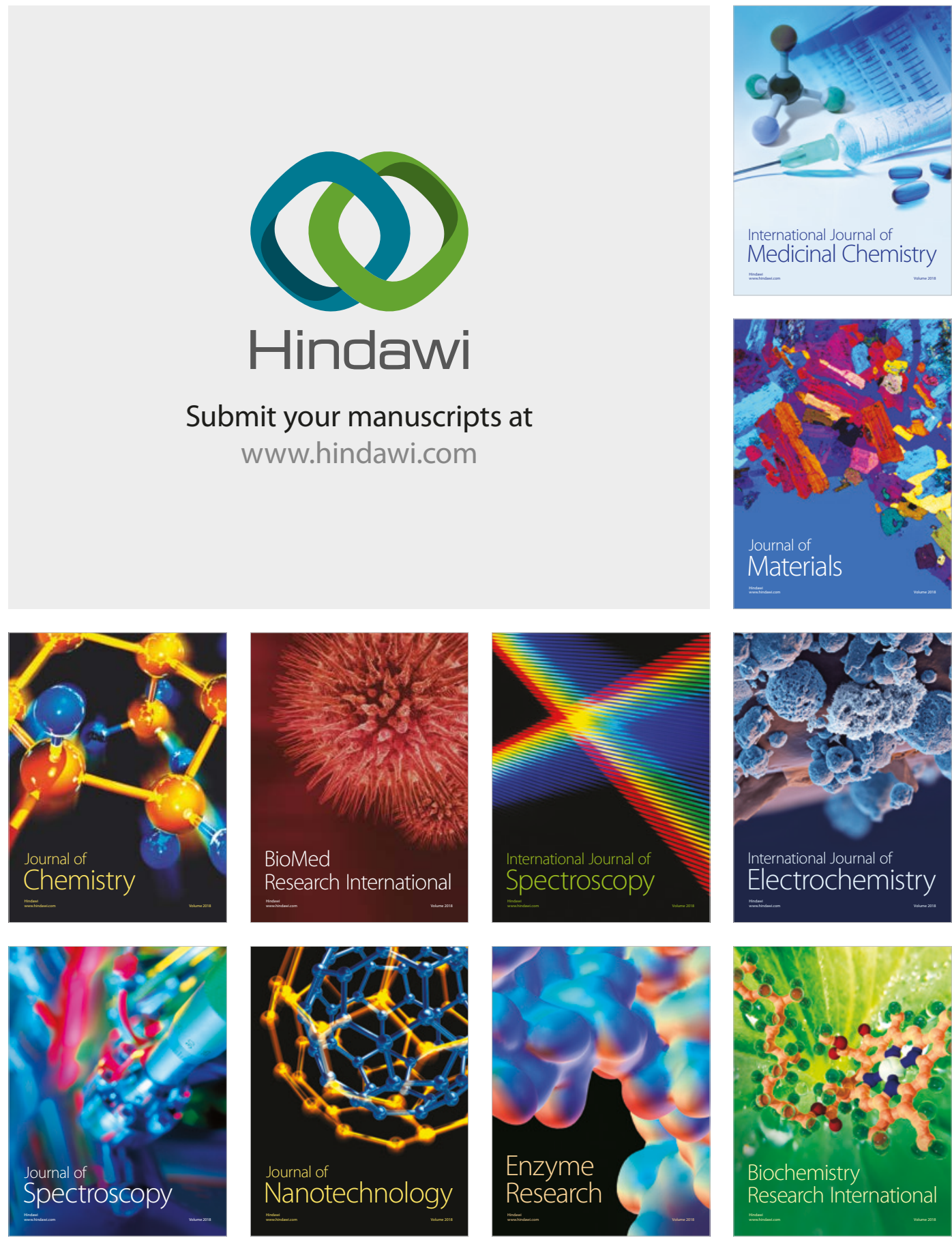
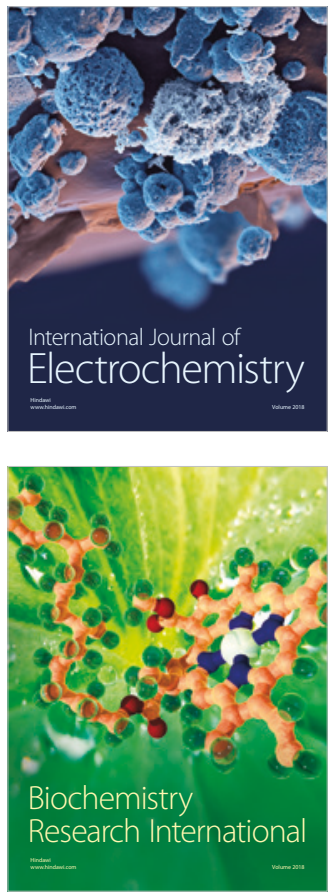